\title{
Malignant Peripheral Nerve Sheath Tumor of the Liver
}

\author{
Satoru Kakizaki ${ }^{1}$, Norio Horiguchi ${ }^{1,2}$, Toshiyuki Otsuka ${ }^{2}$, Daichi Takizawa ${ }^{2}$, \\ Yuichi Yamazaki ${ }^{1}$, Ken Sato ${ }^{1}$, Yoshihiro Ohno ${ }^{3}$, Motoyasu Kusano ${ }^{4}$ and Masanobu Yamada ${ }^{1}$
}

\begin{abstract}
Malignant peripheral nerve sheath tumor (MPNST) of the liver is rare. Most cases of MPNST are accompanied by neurofibromatosis 1 (NF-1, von Recklinghausen's disease). We herein report an autopsy case of MPNST without NF-1 and review the pertinent literature. The tumor occupied the entire lobe of the liver, and was $18 \mathrm{~cm}$ in maximum diameter. The tumor revealed necrosis and cystic changes with hemorrhage and it had also metastasized to the peritoneum. Microscopically, the tumor was composed of pleomorphic spindle cells with hyperchromatic nuclei and mitogenic figures. The spindle cells stained positive for both S-100 and vimentin antibodies.
\end{abstract}

Key words: malignant peripheral nerve sheath tumor, malignant schwannoma

(Intern Med 55: 245-249, 2016)

(DOI: 10.2169/internalmedicine.55.5456)

\section{Introduction}

Malignant peripheral nerve sheath tumors (MPNSTs), which account for $5-10 \%$ of all soft tissue sarcomas, are a rare entity (1-3). MPNSTs commonly arise along the peripheral nerve as well as in the cranial nerve and dorsal spinal roots. Most cases of MPNST are accompanied by neurofibromatosis 1 (NF-1, von Recklinghausen's disease). MPNSTs arising from the liver are extremely rare, with only 10 cases have reported in the literature (3-12). Hepatic MPNST without NF-1 is even rarer (10). We herein report a case of hepatic MPNST without NF-1 and review the pertinent literature.

\section{Case Report}

A 72-year-old woman was admitted to our hospital (ToneChuo Hospital, Gunma, Japan) with a history of a progressively enlarging epigastric mass of 5 months' duration. She had no history of oral contraceptive use. She had no major past- or familial history. On the physiological examination, a large mass with a smooth surface was palpable in the epigastrium. She had no pain or tenderness. The superficial lymph nodes were not palpable. The results of neurological and dermatological examinations were both normal. The patient's liver function test results showed an elevation of aspartate aminotransferase (AST) 51 IU/L, lactate dehydrogenase (LDH) $822 \mathrm{IU} / \mathrm{L}$, and gamma-glutamyl transferase ( $\gamma$ GTP) $123 \mathrm{mU} / \mathrm{L}$. The levels of serum alpha fetoprotein (AFP), carcinoembryonic antigen (CEA), carbohydrate antigen 19-9 (CA19-9) and des- $\gamma$-carboxy prothrombin (DCP) were all within the normal ranges, with the exception of interleukin-2 receptor, the level of which was elevated to 2,170 U/mL (normal range: 122-496 U/mL). Hepatitis B surface antigens and antibodies were not detected. Although there was a slight elevation of hepatitis $\mathrm{C}$ virus antibodies, hepatitis C RNA was not detected. Abdominal computed tomography (CT) revealed a large solid mass measuring 18 $\mathrm{cm}$ in maximum diameter with several low density areas (Fig. 1A). The mass was depicted on contrast-enhanced CT as a low density area that was similar in appearance to a cystic tumor (Fig. 1B). Ultrasonography revealed a large mass with a combined hyper-echoic and cystic pattern in the left lobe of the liver (Fig. 1C, D). A needle biopsy specimen of the tumor was inadequate for making a diagnosis. The cytology of the puncture fluid from the cystic lesion and ascites showed no malignant atypical cells. Cystic liver tumor,

\footnotetext{
${ }^{1}$ Department of Medicine and Molecular Science, Gunma University Graduate School of Medicine, Japan, ${ }^{2}$ Department of Internal Medicine, Tone-Chuo Hospital, Japan, ${ }^{3}$ Department of Pathology, Tone-Chuo Hospital, Japan and ${ }^{4}$ Department of Endoscopy and Endoscopic Surgery, Gunma University Hospital, Japan

Received for publication March 30, 2015; Accepted for publication May 6, 2015

Correspondence to Dr. Satoru Kakizaki, kakizaki@gunma-u.ac.jp
} 

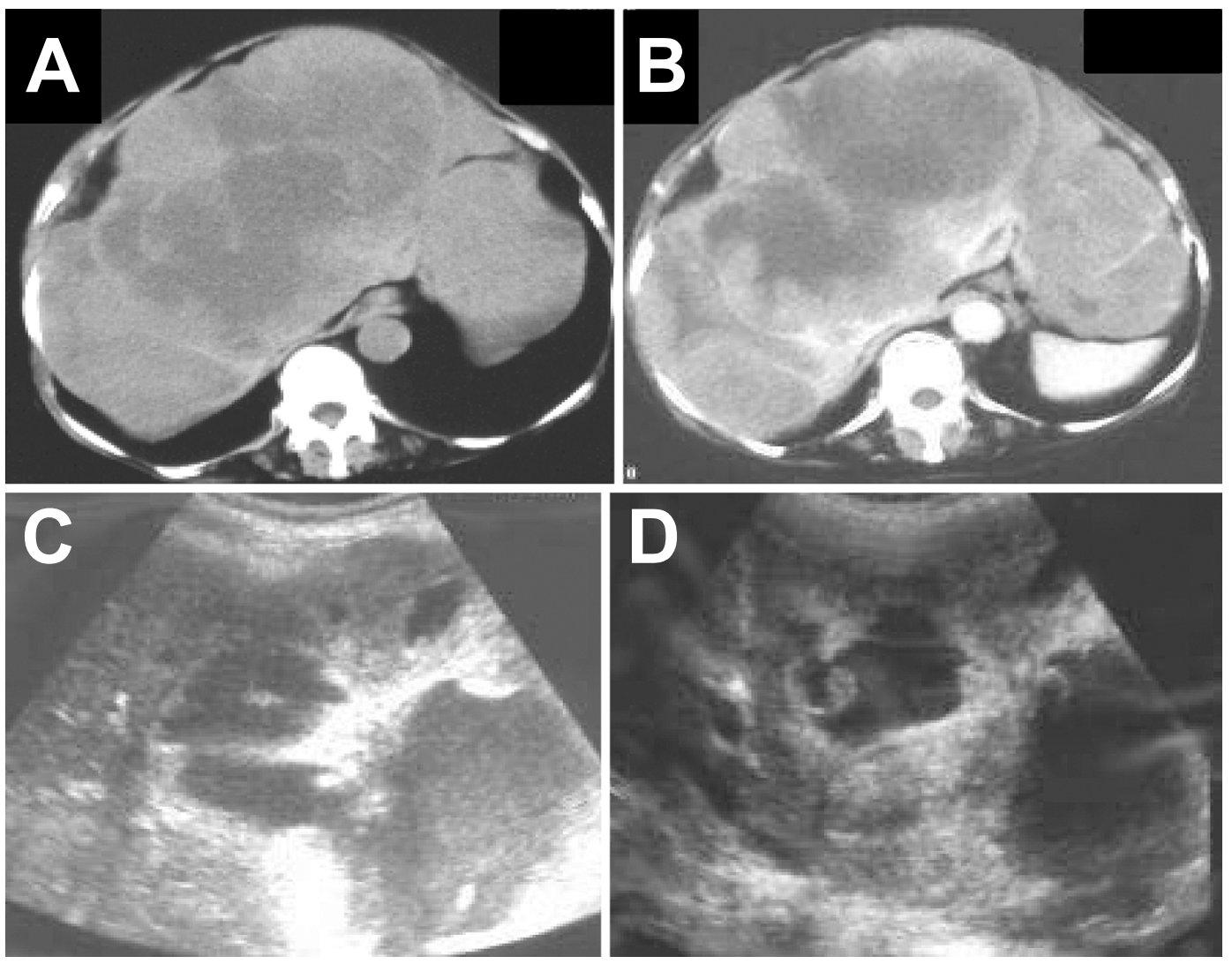

Figure 1. Abdominal computed tomography (CT) and ultrasonography. A: Plain CT. A large solid mass measuring $18 \mathrm{~cm}$ in maximum diameter with several low density areas. B: Contrast-enhanced CT. The mass was depicted as a low density area similar to a cystic tumor. C, D: Ultrasonography revealed a large mass with a combined hyper-echoic and cystic pattern in the left lobe of the liver.
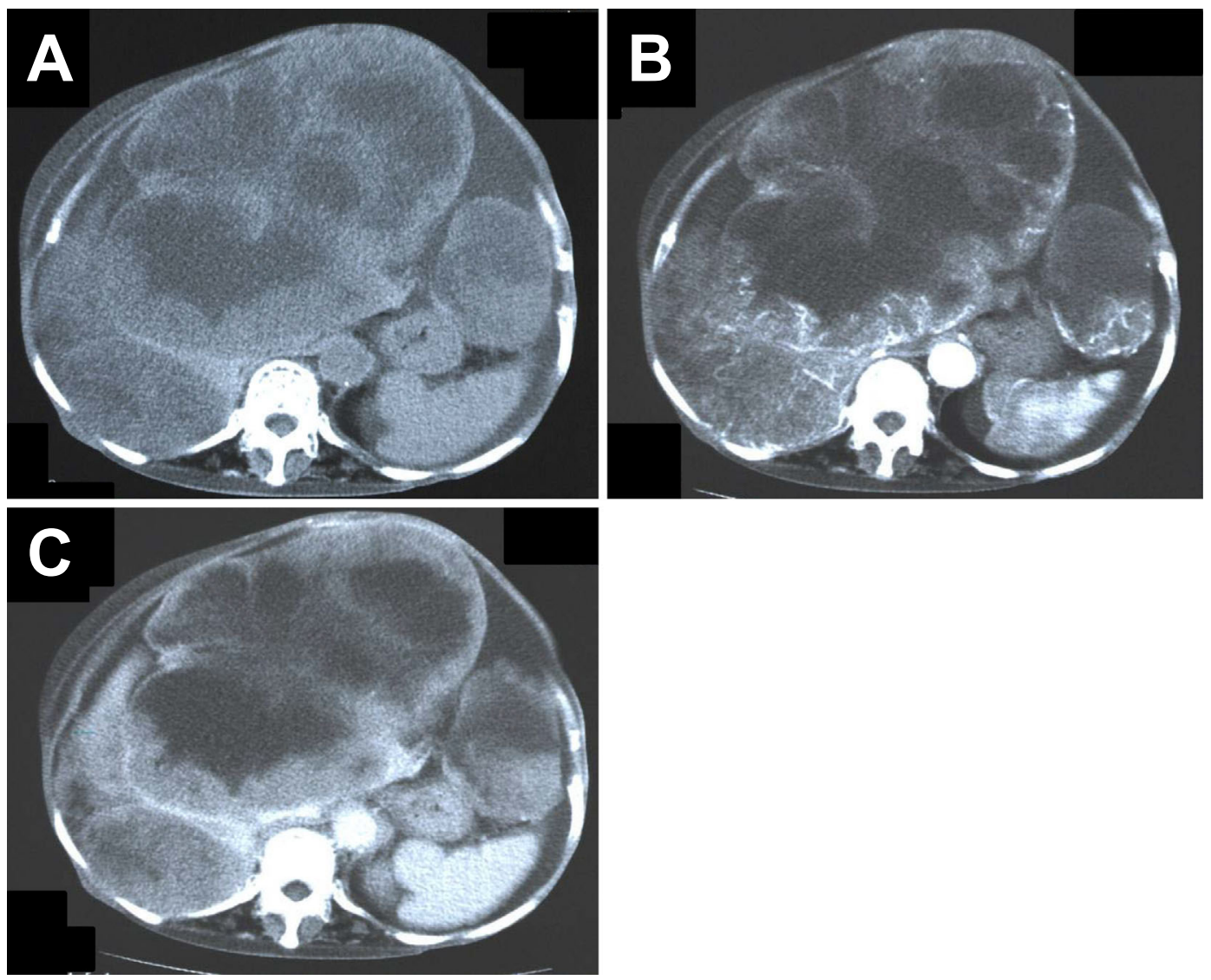

Figure 2. Abdominal CT 1 year after the first admission shows the slow progression of the tumor. 


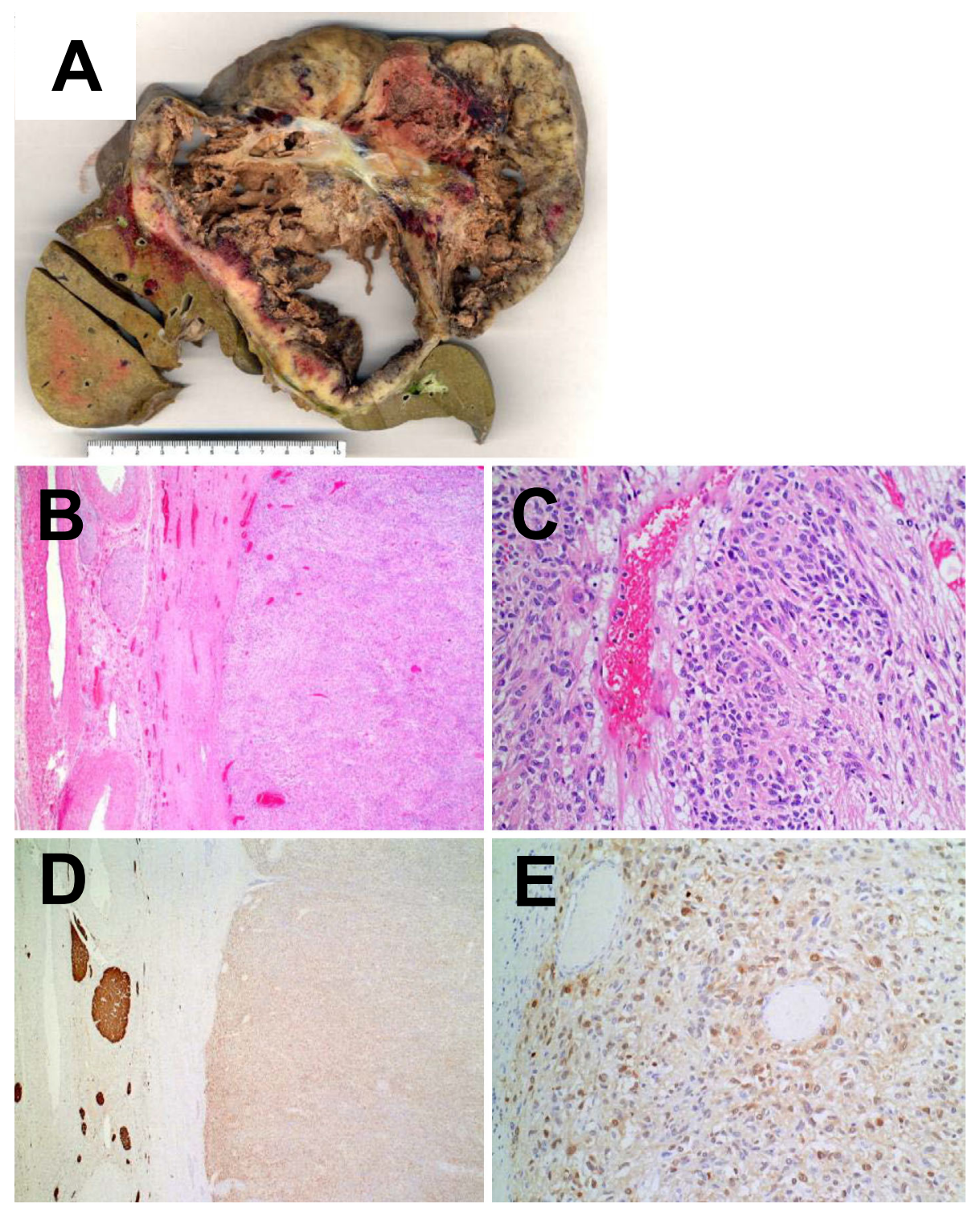

Figure 3. Autopsy findings. A: The cut surface of the liver tumor. The liver was enlarged $(4,360 \mathrm{~g})$, and a tumor mass with a fibrous surface was observed. A whitish-yellow tumor, measuring $24 \times 18 \mathrm{~cm}$, replaced the entire right lobe of the liver. Necrosis and hemorrhage were present in the central area of the tumor. B, C: Microscopic findings. Hematoxylin and Eosin staining shows a spindle cell tumor with cells arranged in whorls and a storiform pattern surrounded by a fibrous capsule. The nuclei are vesicular, spindle-shaped or irregular. Original magnification 40× (B), 400× (C). D, E: Immunohisto-

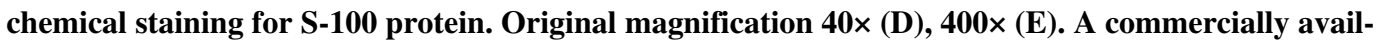
able biotin-streptavidin immunoperoxidase kit and diaminobenzidine were used for coloration.

cystadenocarcinoma, undifferentiated sarcoma, and cystic liver metastasis (including mucinous ovarian carcinoma) were considered in the differential diagnosis of this tumor. The final diagnosis was difficult; clinically, the patient was suspected of having a malignant hepatic cystic tumor with no evidence of tumors in any other parts of her body. Due to the presence of multiple metastases to the peritoneum and the intra-abdominal lymph nodes and her refusal of intensive treatment, the patient was provided with the best supportive care available. Figure 2 shows the abdominal CT findings 1 year after the patient's first admission. The tumors slowly progressed. The patient received palliative care, but finally died of circulatory failure due to the compression of the in- ferior vena cava (IVC) 15 months after her first admission.

An autopsy was performed immediately after death. The body showed severe edema of the lower limbs and abdominal distention. Neither jaundice nor café au lait spots were noted. The liver was enlarged (4,360 g), and a tumor mass with a fibrous surface was found. The cut surface (Fig. 3A) revealed a whitish-yellow tumor, measuring $24 \times 8 \mathrm{~cm}$, which replaced the entire right lobe of the liver, although the parenchyma of the remaining liver was normal in appearance. Necrosis and hemorrhage were present in the central area of the tumor.

A microscopic examination (Fig. 3B, C) showed a spindle cell tumor with cells arranged in whorls and a storiform pat- 
Table. Reported Cases of Malignant Peripheral Nerve Sheath Tumor of the Liver.

\begin{tabular}{|c|c|c|c|c|c|c|c|c|c|}
\hline $\begin{array}{l}\text { Age } \\
\text { (yr) }\end{array}$ & Sex & $\begin{array}{l}\text { Clinical } \\
\text { symptoms }\end{array}$ & $\begin{array}{l}\text { Neurofibromatosi } \\
\text { s type } 1(\mathrm{NF}-1)\end{array}$ & $\begin{array}{l}\text { Size } \\
(\mathrm{cm})\end{array}$ & Diagnosis & Treatment & Follow-up & Outcome & Ref \\
\hline & $23 \mathrm{M}$ & $\begin{array}{l}\text { right upper } \\
\text { quadrant pain } \\
\text { and jaundice }\end{array}$ & Yes & & Autopsy & Conservative & 38 days & died of disease & 3 \\
\hline & $68 \mathrm{M}$ & NA & No & & Autopsy & NA & 37 days & died of disease & 4 \\
\hline & $74 \mathrm{M}$ & epigastric mass & No & & Surgery & Surgery & 21days & $\begin{array}{l}\text { died ( } 21 \text { days } \\
\text { after surgery) }\end{array}$ & 5 \\
\hline & $21 \mathrm{M}$ & $\begin{array}{l}\text { right upper } \\
\text { quadrant pain }\end{array}$ & Yes & & Autopsy & $\begin{array}{l}\text { Hepatic artery } \\
\text { embolization }\end{array}$ & NA & died of disease & 6 \\
\hline & $63 \mathrm{M}$ & $\begin{array}{l}\text { severe } \\
\text { abdominal pain }\end{array}$ & No & & Autopsy & Conservative & $4 \mathrm{mo}$ & died of disease & 7 \\
\hline & $49 \mathrm{M}$ & jaundice & No & 15 & Surgery & Surgery & $3 \mathrm{mo}$ & alive & 8 \\
\hline & $35 \mathrm{~F}$ & $\begin{array}{l}\text { abdominal } \\
\text { distension, } \\
\text { weight loss, and } \\
\text { abdominal pain }\end{array}$ & No & $\mathrm{NA}$ & Biopsy & $\mathrm{NA}$ & NA & NA & 9 \\
\hline & $22 \mathrm{~F}$ & $\begin{array}{l}\text { right upper } \\
\text { quadrant pain } \\
\text { and extreme }\end{array}$ & No & 26 & $\begin{array}{l}\text { Biopsy and } \\
\text { surgery }\end{array}$ & Surgery & NA & $\begin{array}{l}\text { alive ( } 21 \text { days } \\
\text { after surgery) }\end{array}$ & 10 \\
\hline & $83 \mathrm{M}$ & $\begin{array}{l}\text { no symptoms, } \\
\text { incidental }\end{array}$ & No & & Surgery & Surgery & NA & alive & 11 \\
\hline & $71 \mathrm{M}$ & $\begin{array}{l}\text { right upper } \\
\text { quadrant pain } \\
\text { and abdominal }\end{array}$ & No & 2 & Surgery & Surgery & NA & alive & 12 \\
\hline & $73 \mathrm{~F}$ & epigastric mass & No & 18 & Autopsy & Conservative & $16 \mathrm{mo}$ & died of disease & present \\
\hline
\end{tabular}

tern. The tumor contained necrosis and was surrounded by a fibrous capsule. The nuclei were vesicular, spindle-shaped or irregular. Mitosis was observed in 1/50 high-power fields and the MIB-1 labeling index was $0.5-1.0 \%$. An immunohistochemical analysis, revealed that the samples were positive for S-100 protein (Fig. 3D, E) and vimentin and negative for c-kit (CD117), epithelial membrane antigen (EMA), keratin, desmin, and alpha-smooth muscle actin ( $\alpha$-SMA). We ultimately diagnosed the patient with an MPNST of liver origin according to the histological findings.

\section{Discussion}

MPNST has historically been referred to by a variety of names, including malignant schwannoma, neurofibrosarcoma, neurogenic sarcoma, and malignant neurilemmoma $(1,13)$. MPNSTs are characterized as arising from a peripheral nerve, mostly from Schwann cells, and are often associated with NF-1 $(1,13)$. The majority of NF1associated MPNSTs arise from preexisting plexiform neurofibromas $(2,14)$. The lifetime incidence of MPNSTs in NF1 patients is $8-13 \%$, whereas the general population has an incidence of $0.01 \%(2,14)$.

A large study with 120 cases during a 71-year period by Ducatman et al. (2) included $62(52 \%)$ patients with NF-1. The majority of MPNSTs arise either from neurofibromas or de novo from normal peripheral nerves (2). MPNSTs mostly arise in the trunk (approximately 50\%), followed by the extremities and the head and neck region $(2,15)$. Distant metastases to the lung, lymph nodes, and liver have also been reported $(2,15,16)$. However, primary hepatic MPNST is extremely rare (3-12). To the best of our knowledge, only 11 cases (including our own case), of an MPNST arising from the liver have been reported (Table). The median age at the onset of disease in the 11 cases was 63 years and there was a male predominance $(8 / 11)$; the patients presented with a range of symptoms including right upper quadrant pain, liver mass, abdominal fullness, and jaundice (3-12). The biochemical investigations did not always demonstrate altered liver function (3-12). CT demonstrated a heterogeneous rapidly enlarging liver mass $7-30 \mathrm{~cm}$ in size (3-12). The inability to perform a surgical resection was associated with a poor prognosis.

MPNST with NF1 is associated with lower survival rates in comparison to MPNST without NF-1 $(2,17,18)$. Sordillo et al. (18) analyzed 165 patients with MPNSTs and found that the five-year survival rates of patients with and without NF-1 were $23 \%$ and $47 \%$, respectively. The reasons for the poor prognosis in NF-1 patients included a tendency toward larger tumors, poorer differentiation, higher rates of metastasis and multifocality $(2,17-19)$. The overall survival rate was even poorer in children with NF1, and the presence of NF-1 was identified as a significant poor prognostic factor (20). The prognosis of hepatic MPNSTs with or without NF-1 is not certain due to the rarity of the condition and the lack of case descriptions.

Because MPNST is a rare disease and because patients have been treated by a range of different modalities, large modern clinical studies are lacking (16). MPNSTs are usually associated with a poor prognosis (15). Wong et al. (15) analyzed 134 cases of MPNST and reported that the 5-year survival rate was $52 \%$, with a $49 \%$ risk of local recurrence. 
The tumor size, location (favorable: extremities), patient history of NF1 (unfavorable), tumor grade and the integrity of the surgical margins were found to be prognostic factors $(15,16)$. The main treatment for MPNSTs is surgical resection; chemotherapy and radiotherapy are often ineffective $(15,16)$. A certain level of success has been reported with the use of doxorubicin alone or in combination with other drugs (21). However, the effects of chemotherapy and radiotherapy remain unclear.

Immunohistoreactivity for S-100 protein is typically found in $50-70 \%$ of MPNSTs and is thus less frequent than in benign peripheral nerve sheath tumors (16). The staining of tumor specimens is generally focal, and the number of immunoreactive cells is small in comparison to neurofibroma and schwannoma, reflecting either a loss of differentiation or a shift from a Schwann (S-100 protein-positive) cell population to a perineural (S-100 protein-negative) cell population. Regarding the histological characteristics it is unknown how the histology of MPNST arising from the liver differs from MPNST arising from other organs. The further accumulation of cases is required to obtain this information.

In conclusion, we herein reported a rare case of hepatic MPNST without NF-1 and reviewed the pertinent literature. Because MPNST is a rare disease, large modern clinical studies are lacking. The accumulation of cases of hepatic MPNST without NF-1 will be helpful for shaping the future management and treatment strategies for MPNST.

The authors state that they have no Conflict of Interest (COI).

\section{References}

1. Perrin RG, Guha A. Malignant peripheral nerve sheath tumors. Neurosurg Clin N Am 15: 203-216, 2004.

2. Ducatman BS, Scheithauer BW, Piepgras DG, Reiman HM, Ilstrup DM. Malignant peripheral nerve sheath tumors. A clinicopathologic study of 120 cases. Cancer 57: 2006-2021, 1986.

3. Young SJ. Primary malignant neurilemmona (schwannoma) of the liver in a case of neurofibromatosis. J Pathol 117: 151-153, 1975.

4. Shmurun RI, Chibisov VN. Malignant neurinoma of the liver. Arkh Patol 39: 69-71, 1977.

5. Tuder RM, Moraes CF. Primary semimalignant Schwannoma of the liver. Light and electron microscopic studies. Pathol Res Pract 178: 345-348, 1984.
6. Lederman SM, Martin EC, Laffey KT, Lefkowitch JH. Hepatic neurofibromatosis, malignant schwannoma, and angiosarcoma in von Recklinghausen's disease. Gastroenterology 92: 234-239, 1987.

7. Morikawa Y, Ishihara Y, Matsuura N, Miyamoto H, Kakudo K. Malignant schwannoma of the liver. Dig Dis Sci 40: 1279-1282, 1995.

8. Fiel MI, Schwartz M, Min AD, Sung MW, Thung SN. Malignant schwannoma of the liver in a patient without neurofibromatosis: a case report and review of the literature. Arch Pathol Lab Med 120: 1145-1147, 1996.

9. Sheikh MY, Husen YA, Pervez S, Khalid TR, Jaffer N, Afzal M. Computed tomography appearance of malignant schwannoma of the liver. Can Assoc Radiol J 47: 183-185, 1996.

10. Kóbori L, Nagy P, Máthé $Z$, et al. Malignant peripheral nerve sheath tumor of the liver: a case report. Pathol Oncol Res 14: 329-332, 2008

11. Iddings DM, Wright BE, Bilchik A. A rare cause of primary hepatic neoplasm: malignant peripheral nerve sheath tumor in the age of modern liver surgery. Am Surg 74: 47-50, 2008.

12. Subramaniam K, Dessauvagie $B$, Hardie $M$, et al. Malignant peripheral nerve sheath tumour of the liver. Pathology 44: 265-267, 2012.

13. Grobmyer SR, Reith JD, Shahlaee A, Bush CH, Hochwald SN. Malignant Peripheral Nerve Sheath Tumor: molecular pathogenesis and current management considerations. J Surg Oncol 97: 340349, 2008.

14. Kahn J, Gillespie A, Tsokos M, et al. Radiation therapy in management of sporadic and neurofibromatosis type 1-associated malignant peripheral nerve sheath tumors. Front Oncol 4: 324, 2014.

15. Wong WW, Hirose T, Scheithauer BW, Schild SE, Gunderson LL. Malignant peripheral nerve sheath tumor: analysis of treatment outcome. Int J Radiat Oncol Biol Phys 42: 351-360, 1998.

16. Stark AM, Buhl R, Hugo HH, Mehdorn HM. Malignant peripheral nerve sheath tumours--report of 8 cases and review of the literature. Acta Neurochir (Wien) 143: 357-363, 2001.

17. Minovi A, Basten O, Hunter B, Draf W, Bockmühl U. Malignant peripheral nerve sheath tumors of the head and neck: management of 10 cases and literature review. Head Neck 29: 439-445, 2007.

18. Sordillo PP, Helson L, Hajdu SI, et al. Malignant schwannoma-clinical characteristics, survival, and response to therapy. Cancer 47: 2503-2509, 1981.

19. Ghosh BC, Ghosh L, Huvos AG, Fortner JG. Malignant schwannoma. A clinicopathologic study. Cancer 31: 184-190, 1973.

20. Carli M, Ferrari A, Mattke A, et al. Pediatric malignant peripheral nerve sheath tumor: the Italian and German soft tissue sarcoma cooperative group. J Clin Oncol 23: 8422-8430, 2005.

21. Goldman RL, Jones SE, Heusinkveld RS. Combination chemotherapy of metastatic malignant schwannoma with vincristine, adriamycin, cyclophosphamide, and imidazole carboxamide: a case report. Cancer 39: 1955-1958, 1977.

(C) 2016 The Japanese Society of Internal Medicine http://www.naika.or.jp/imonline/index.html 